\title{
A rare homozygous MFSD8 single-base-pair deletion and frameshift in the whole genome sequence of a Chinese Crested dog with neuronal ceroid lipofuscinosis
}

Juyuan Guo', Dennis P O'Brien², Tendai Mhlanga-Mutangadura', Natasha J Olby ${ }^{3}$, Jeremy F Taylor ${ }^{4}$, Robert D Schnabel', Martin L Katz ${ }^{5}$ and Gary S Johnson ${ }^{1^{*}}$

\begin{abstract}
Background: The neuronal ceroid lipofuscinoses are heritable lysosomal storage diseases characterized by progressive neurological impairment and the accumulation of autofluorescent storage granules in neurons and other cell types. Various forms of human neuronal ceroid lipofuscinosis have been attributed to mutations in at least 13 different genes. So far, mutations in the canine orthologs of 7 of these genes have been identified in DNA from dogs with neuronal ceroid lipofuscinosis. The identification of new causal mutations could lead to the establishment of canine models to investigate the pathogenesis of the corresponding human neuronal ceroid lipofuscinoses and to evaluate and optimize therapeutic interventions for these fatal human diseases.

Case presentation: We obtained blood and formalin-fixed paraffin-embedded brain sections from a rescue dog that was reported to be a young adult Chinese Crested. The dog was euthanized at approximately 19 months of age as a consequence of progressive neurological decline that included blindness, anxiety, and cognitive impairment. A diagnosis of neuronal ceroid lipofuscinosis was made based on neurological signs, magnetic resonance imaging of the brain, and fluorescence microscopic and electron microscopic examination of brain sections. We isolated DNA from the blood and used it to generate a whole genome sequence with 33-fold average coverage. Among the 7.2 million potential sequence variants revealed by aligning the sequence reads to the canine genome reference sequence was a homozygous single base pair deletion in the canine ortholog of one of 13 known human NCL genes: MFSD8:c.843delT. MFSD8:c.843delT is predicted to cause a frame shift and premature stop codon resulting in a truncated protein, MFSD8: p.F282Lfs 13*, missing its 239 C-terminal amino acids. The MFSD8:c.843delT allele is absent from the whole genome sequences of 101 healthy canids or dogs with other diseases. The genotyping of archived DNA from 1478 Chinese Cresteds did not identify any additional MFSD8:C.843delT homozygotes and found only one heterozygote.
\end{abstract}

Conclusion: We conclude that the neurodegenerative disease of the Chinese Crested rescue dog was neuronal ceroid lipofuscinosis and that homozygosity for the MFSD8:C.843delT sequence variant was very likely to be the molecular-genetic cause of the disease.

Keywords: MFSD8, Neuronal ceroid lipofuscinosis, Chinese Crested, Whole genome sequence

\footnotetext{
*Correspondence: johnsongs@missouri.edu

'Department of Veterinary Pathobiology, College of Veterinary Medicine, University of Missouri, Columbia, MO, USA

Full list of author information is available at the end of the article
} 


\section{Background}

The neuronal ceroid lipofuscinoses (NCLs) are heritable lysosomal storage diseases characterized by progressive cognitive decline, motor impairment, vision loss, seizures, and progressive brain atrophy together with the accumulation of autofluorescent lysosomal storage bodies in the brain, the retina and other tissues [1]. Human NCLs have been attributed to mutations in at least 13 different genes [2-15]. As indicated in Table 1, mutations in the canine orthologs of 7 of these genes have been associated with NCL in various dog breeds [16-24]. In addition, a neurodegenerative disease in American Staffordshire Terriers with an ARSG mutation was initially described as an NCL [25]; however, based on a recent description of Arsgknockout mice [26], the American Staffordshire Terrier disease was more likely a mucopolysaccaridosis.

With written consent from the owner we obtained blood and formalin-fixed brain tissue from a young adult Chinese Crested that was euthanized due to progressive neurological decline accompanied by brain atrophy. The clinical signs suggested that neuronal ceroid lipofuscinosis was the underlying disease. The fixed tissue was evaluated for the presence of the autofluorescent storage material that is characteristic of the NCLs. DNA was extracted from the blood and used to generate a whole genome sequence (WGS) which provided an opportunity to identify the disease-causing mutation.

\section{Case presentation}

An approximately 1.5-year-old, male neutered Chinese Crested presented for disorientation, blindness and fearful behavior. The dog had been adopted as a rescue at approximately 4 months of age. The dog had always licked compulsively. At about 1 year of age, he became withdrawn, less playful, nervous, and fearful. One month prior to admission, he developed dilated pupils and began bumping into objects. He also had episodes of behavioral arrest. Ophthalmologic examination revealed an absent menace response, a positive dazzle reflex, and a sluggish, incomplete pupillary light reflex. Ocular exam revealed no abnormalities, and an ERG was within normal limits. Imaging of the brain was performed with a $1.5 \mathrm{~T}$ GE MRI which included T2, FLAIR, GRE T1*, and T1 pre- and post-contrast sequences. T2 weighted images showed a lack of distinction between grey matter and white matter. Enlarged ventricles and increased prominence of sulci of the cerebrum and cerebellum suggested diffuse brain atrophy (Figure 1).

Over the next few weeks, the Chinese Crested became more disoriented and stopped responding to the owner. He would yelp in fear randomly and resisted being held. He was sleeping more and developed pica. On presentation, he was agitated and hyper-responsive to stimuli. He showed a sensory ataxia in all 4 limbs, with normal proprioceptive positioning. Other than the previously described ophthalmologic abnormalities, cranial nerves were normal, as were the spinal reflexes. Cerebrospinal fluid analysis was within normal limits. A progressive neurodegenerative disease was suspected, and the dog was euthanized.

At necropsy, slices of the cerebellum and cerebral cortex were fixed in formalin and embedded in paraffin for routine histological examination. Unstained sections of these tissues were deparaffinized and examined with fluorescence microscopy as previously described [27]. Both the cerebellum and the cerebral cortex exhibited massive intracellular accumulations of autofluorescent material with a golden yellow emission under blue light illumination (Figure 2). In the cerebellum storage material was most prominent in the Purkinje cells, but substantial amounts of this material were also present in the granular

Table 1 Human genes known to harbor NCL-causing mutations and their orthologs known to cause NCL in dogs

\begin{tabular}{llll}
\hline Human disease & Mutant gene & Mutant protein & Canine disease described? \\
\hline CLN1 & PPT1 [2] & Palmitoyl-protein thioesterase 1 & Yes [16] \\
CLN2 & TPP1 [3] & Tripeptidyl peptidase 1 & Yes [17] \\
CLN3 & CLN3 [4] & CLN3 & No \\
CLN4 & DNAJC5 [5] & DNAJC5 & Yes [18] \\
CLN5 & CLN5 [6] & CLN5 & Yes [19] \\
CLN6 & CLN6 [7,8] & CLN6 & Yes [Current report] \\
CLN7 & MFSD8 [9] & MFSD8 & Yes [20,21] \\
CLN8 & CLN8 [10] & CLN8 & Yes [22] \\
CLN10 & Cathepsin D & No \\
CLN11 & Granulin $[1]$ & ATP13A2 & Yes [23,24] \\
CLN12 & GRN [12] & Cathepsin F & No \\
CLN13 & ATP13A2 [13] & KCTD7 & No \\
\hline CLN14 & CTSF [14] & &
\end{tabular}



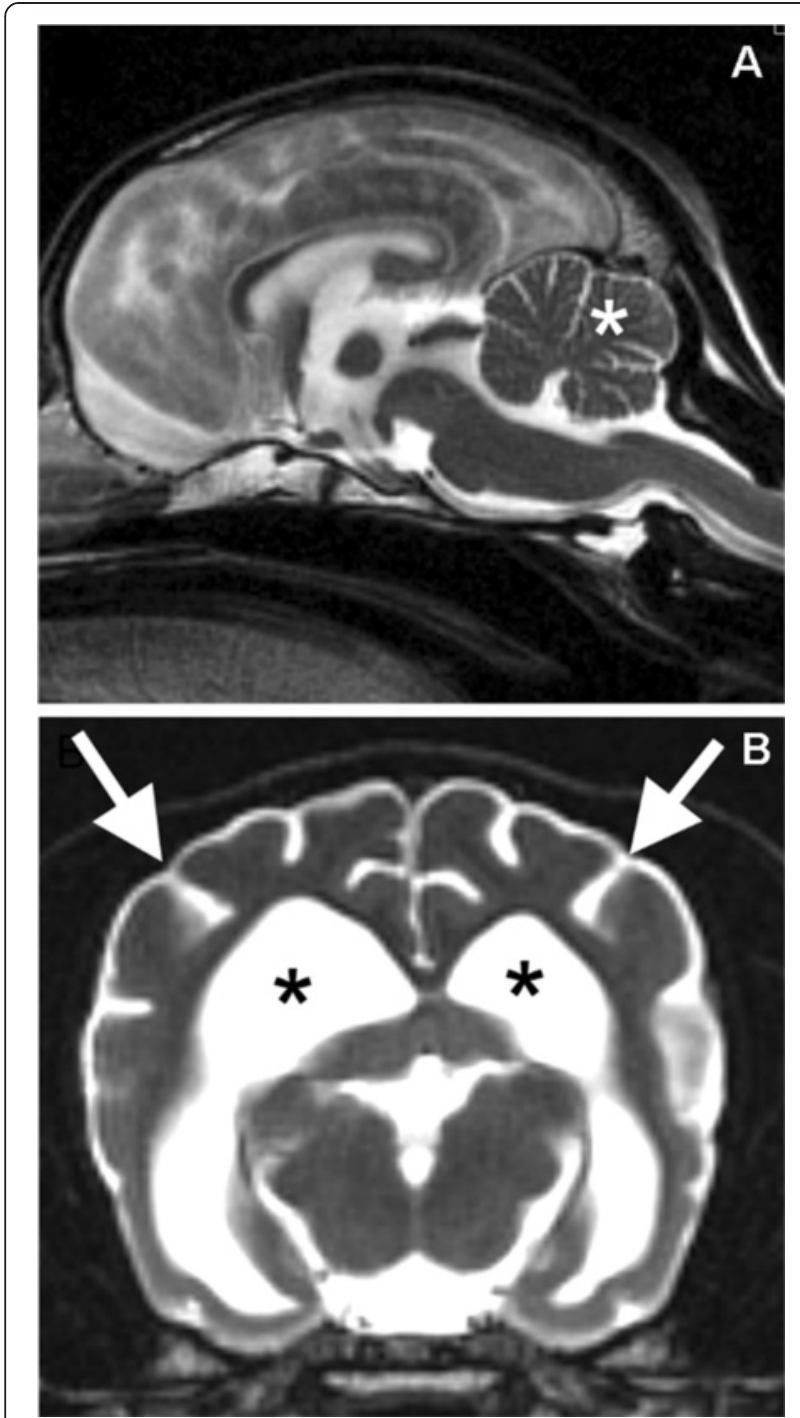

Figure 1 T2 weighted MRI from the affected dog. In the sagittal plane (A) prominent sulci in the cerebellum (asterisk) and the prominent fourth ventricle below the cerebellum indicates atrophy. In the transverse plane (B), prominent sulci in the cerebrum (arrows) and dilated lateral ventricles (asterisks) indicate atrophy. The distinction between grey matter and white matter in the remaining cerebral cortex is obscured.

layer (Figure 2A and B). Perinuclear accumulations of autofluorescent storage granules were observed in neurons throughout the cerebral cortex (Figure 2C). Additional sections of the cerebellum were immunostained for glial fibrillary acidic protein (GFAP) as previously described [28]. In the cerebellar medulla there was a dramatic increase in GFAP staining intensity with concentration of the staining in glial cell perinuclear cytoplasm as well as in the cell processes (Figure 3A). By comparison, GFAP staining in the cerebellar medulla from a normal 12-month-old Beagle was much less intense and was more diffuse (Figure 3B). The GFAP staining pattern observed in the affected dog is characteristic of the
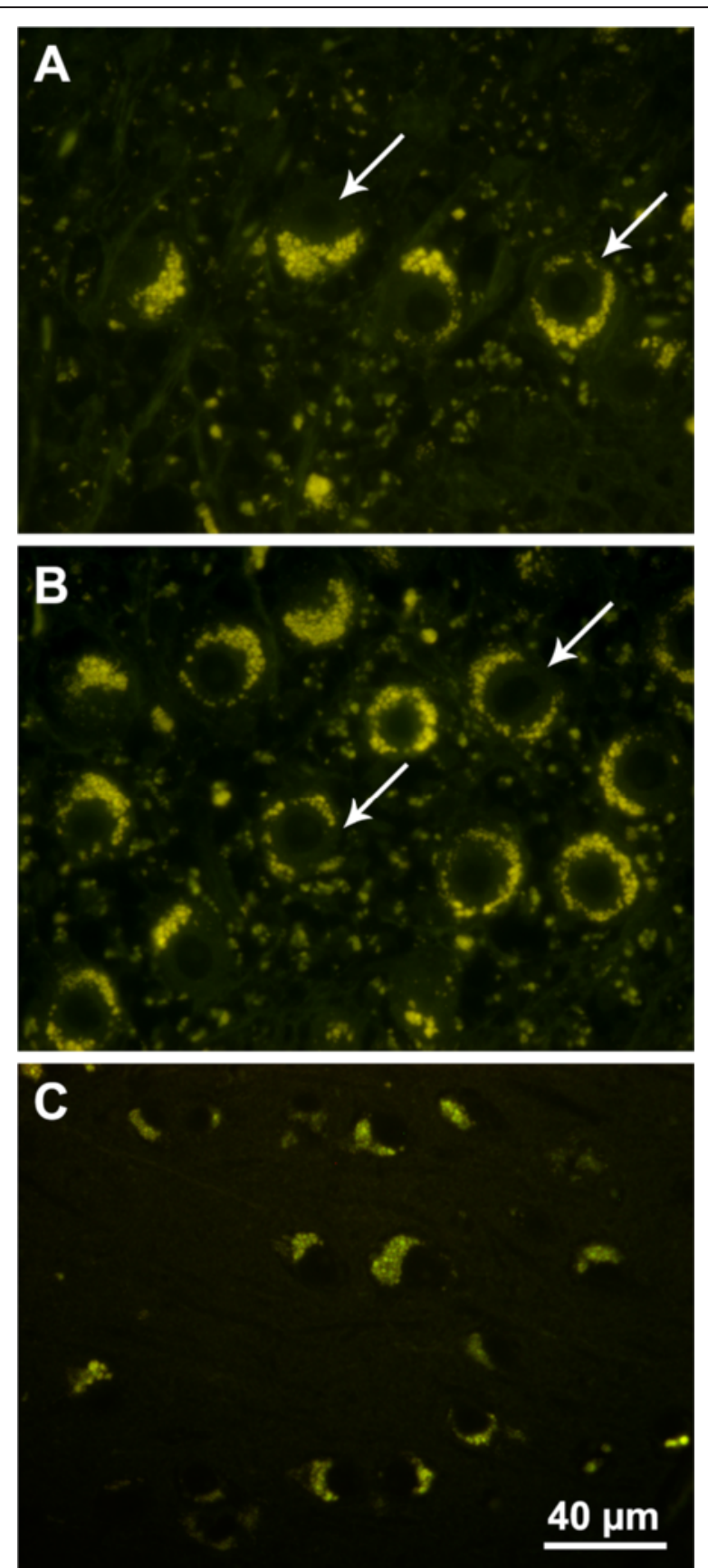

Figure 2 Fluorescence micrographs of brain sections of cerebellum ( $A$ and $B$ ) and cerebral cortex (C) demonstrating the massive intracellular accumulation of yellow-emitting autofluorescent storage bodies. In the cerebellum the storage body accumulation was most pronounced in the Purkinje cells (arrows in $\mathbf{A}$ and $\mathbf{B}$ ). The section in (A) was cut perpendicular to the plane of the Purkinje cell layer and the section in (B) was cut parallel to the plane of the Purkinje cell layer. The storage body accumulation in the neurons of the cerebral cortex was perinuclear and asymmetric. Bar in (C) indicates the magnification for all 3 micrographs. 

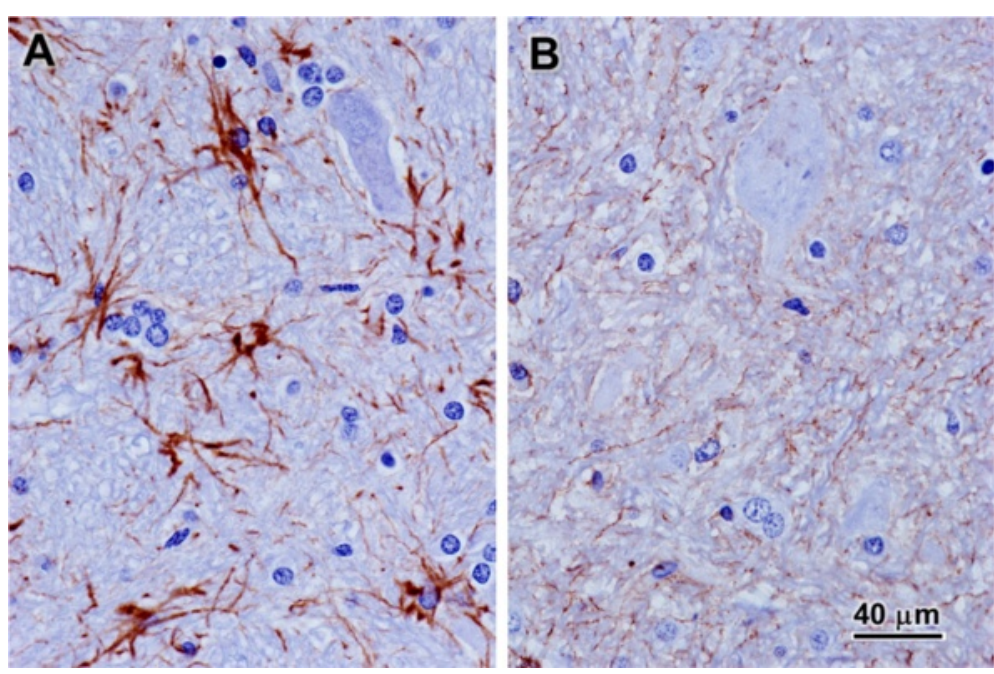

Figure 3 Micrographs of sections of the cerebellar medulla from the Chinese Crested with signs of neuronal ceroid lipofuscdinosis (A) and from a normal 12-month-old Beagle (B). The sections were immunostained for GFAP (brown stain) and were counterstained with hematoxylin (blue). Bar in (B) indicates the magnification of both micrographs.

astrogliosis that occurs in many neurodegenerative and neuroinflammatory conditions $[29,30]$.

To investigate the ultrastructural appearance of the storage material, deparaffinized and rehydrated tissue from the cerebellum was post-fixed in osmium tetroxide and processed for electron microscopic examination using established procedures [31]. The storage material consisted primarily of aggregates of lamellar structures organized in various patterns similar to those previously described as fingerprint in appearance (Figure 4). However, none of the crystalline cross-hatched structures of classical fingerprint inclusions characteristic of some NCLs were seen [32].
DNA was isolated from the blood as previously described [20] and submitted to the University of Missouri DNA Core Facility for library preparation and sequencing. Two PCR-free paired-end libraries were created with the Illumina TruSeq DNA PCR-Free Sample Preparation Kit. One had a fragment size of approximately $350 \mathrm{bp}$ and the fragment size of the other was approximately $550 \mathrm{bp}$. Each library was sequenced on a flow-cell lane of an Illumina HiSeq 2000 sequencer. The adaptors were trimmed with custom Perl scripts and the adaptortrimmed reads were deposited in the Sequence Read Archive (accession SRR1594157). MaSuRCA v2.2.2 software [33] was used to error correct the adapter-trimmed
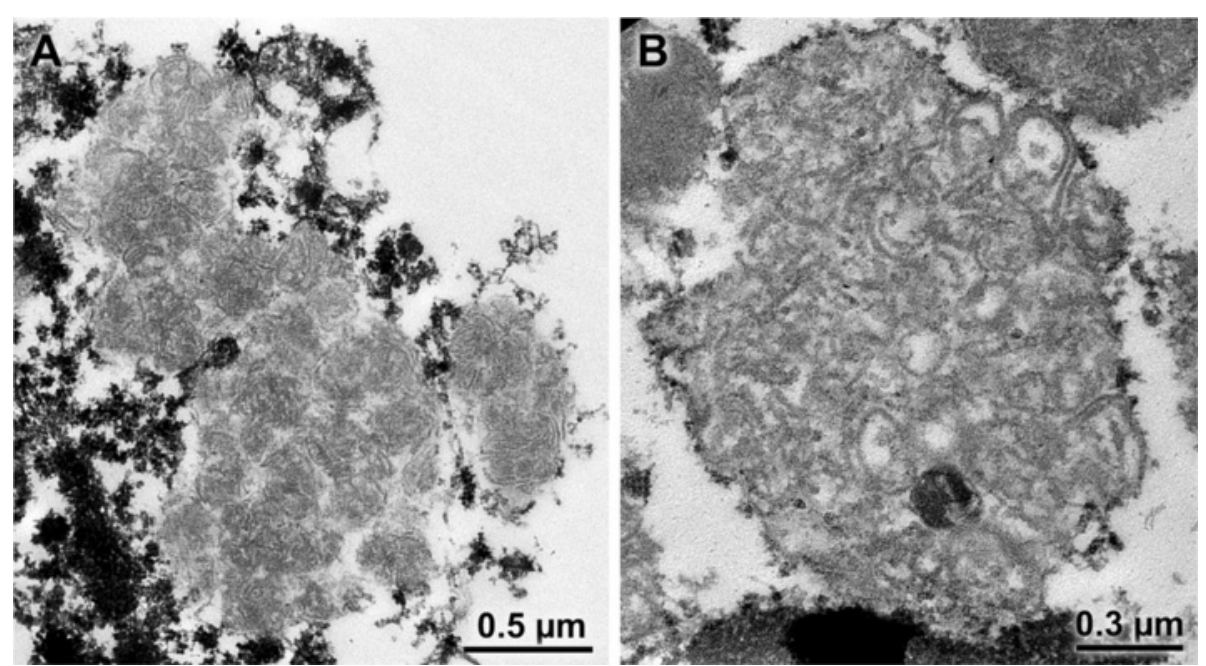

Figure 4 Electron micrographs of the storage material from cerebellar Purkinje cells. The storage bodies contained spherical aggregates of lamellar material that were condensed in some storage bodies (A) and more loosely organized in others (B). 
reads. The trimmed and error-corrected reads were aligned to the CanFam3.1 reference genome assembly with NextGENe software (SoftGenetics), which was also used for the identification and initial categorization of the sequence variants. Likely false positive variant calls were identified and removed with custom Perl scripts. The genome-wide average coverage was 33 fold. The 7.2 million potential sequence variants were uploaded to a custom PostgreSQL database that also contained the variant calls from another 101 canid WGSs. Fortythree of these control WGSs were from our group and 58 were from others listed in the Acknowledgements. Almost all of the NCLs are rare, recessively inherited diseases, so we used an algorithm that identifies variants that were homozygous in the affected dog, absent from the 101 control WGS and predicted to alter the primary structure of the gene products. Sixty seven of the sequence variants met these criteria (Additional file 1: Table S1); however, none of them were from any of the 13 known human NCL genes.

One of the 67 homozygous, unique, coding variants in the Chinese Crested's WGS was PCYOX1:c.1064C $>T$ (Figure 5A). This missense mutation predicts a p.T355I amino acid substitution in the gene product, prenylcysteine lyase. We considered PCYOX1:c.1064C $>T$ to be a candidate for causality because earlier investigators had predicted that prenylcysteine lyase deficiencies might cause NCL [34]. Thus, we used flanking PCR primers 5'-TCTCCTGTTTAT TATAGCAAG-3' and 5'-TTTGAGAACATTGATATGCTT3 ' to amplify and verify the sequence variant by automated Sanger sequencing (Figure 5B). We next devised a TaqMan allelic discrimination assay [35] to genotype archived DNA samples at PCYOX1:c.1064C $>T$. For this assay the PCR primers were 5'-CCATCAGTATTACCAACATATAGTGA CAACT-3' and 5'-GGTGGTTAAGATTGTACTGAGATC GA-3' and the competing probes were 5'VIC-AGCTAA AAAGAATTGAATTC-MBG-3' (variant allele) and 5'-FAMAGCTAAAAAGAGTTGAATTC-MBG-3' (reference allele). We used this assay to genotype archived samples from 325 randomly selected Chinese Cresteds and found that 219 samples were homozygous for the reference c.1064C allele, 86 samples were heterozygous and 20 samples were homozygous for the variant $c .1064 T$ allele. Thus, the $T$ allele frequency for this random cohort of Chinese Cresteds was 0.19 - much higher than would be expected if c.1064T homozygosity were the cause of this rare NCL. A check of the clinical records indicated that 2 of the c.1064T homozygotes were over 10 years old and 
considered by their owners to be healthy. It is, therefore, unlikely that the PCYOX1:c.1064T allele causes or contributes to the Chinese Crested's NCL. This conclusion is consistent with a report that nullizygous Pcyox 1 knockout mice do not show clinical signs of disease [36].

Because a plausible relationship between NCL and the other homozygous, unique, coding variants was not apparent, we tried a different strategy for mutation discovery. We used the NextGENeViewer to observe the Chinese Crested alignment and identified sequence variants by scanning through all 130 coding exons in the canine orthologs of the 13 genes associated with human NCL
(Table 1). The results are summarized in Table 2 . No variants were found in the coding exons of PPT1, DNAJC5, CLN5, CTSD, or KCTD7. In and around the coding exons of the other 8 candidate genes, we found 26 sequence variants including 14 synonymous mutations that are unlikely to cause disease. In addition, we found 6 missense mutations, 4 intronic variants within 8 bp of an exon where they could affect exon splicing, one complex deletion-insertion that results in the deletion of 7 codons and the insertion of 2 codons, and a single-base deletion and frame shift. The missense mutations, the intronic variants and the complex deletion-insertion were all common

Table 2 Homozygous variants in the coding exons of NCL genes in the WGS of the Chinese Crested with NCL

\begin{tabular}{|c|c|c|c|c|c|}
\hline \multirow[t]{2}{*}{ Gene } & \multirow[t]{2}{*}{ Exons with no variants } & \multicolumn{4}{|c|}{ Variants } \\
\hline & & Exon & cDNA change & A.A. change & Comment \\
\hline \multirow[t]{2}{*}{$T P P 1$} & $1-6,8-12$ & 7 & c. $711 A>G$ & p.A237A & Silent mutation \\
\hline & & 7 & $c .885 C>T$ & p.P295P & Silent mutation \\
\hline PPT1 & $1-9$ & & & & \\
\hline \multirow[t]{3}{*}{ CLN3 } & $1,2,4-13$ & 3 & c. $209 A>G$ & p.E70G & Common allele \\
\hline & & 14 & C.1057-3 T>C & & Common allele \\
\hline & & 15 & C. $1309 C>T$ & p.L437L & Silent mutation \\
\hline DNAJC5 & $1-4$ & & & & \\
\hline CLN5 & $1-4$ & & & & \\
\hline \multirow[t]{2}{*}{ CLN6 } & $2,3,5-7$ & 1 & $c .86 A>G$ & p.R29K & Common allele \\
\hline & & 4 & c. $327 \mathrm{G}>\mathrm{T}$ & p.L109L & Silent mutation \\
\hline MFSD8 & $1-7,9-12$ & 8 & c.846delT & p.F282fs & Unique allele \\
\hline CLN8 & 2 & 1 & c. $327 A>G$ & p.T109T & Silent mutation \\
\hline CTSD & $1-9$ & & & & \\
\hline \multirow[t]{2}{*}{ GRN } & $1-9,11$ & 10 & c.1326_1344delins & p.LPPAPTH 442_448FC & Common allele \\
\hline & & & CTGC & & \\
\hline \multirow[t]{15}{*}{ ATP13A2 } & $2,4,6,7,9,10,12-14,16-18,20-23,26,27$ & 1 & c. $208 \mathrm{G}>\mathrm{A}$ & p.A70T & Common allele \\
\hline & & 3 & c.509A $>\mathrm{G}$ & p.H170R & Common allele \\
\hline & & 5 & c. $606-8 A>G$ & & Common allele \\
\hline & & 5 & c. $639 C>T$ & p.D213D & Silent mutation \\
\hline & & 6 & c.726T>G & p.R242R & Silent mutation \\
\hline & & 6 & c.728T>C & p.M243T & Common allele \\
\hline & & 8 & C.891T>C & p.Y297Y & Silent mutation \\
\hline & & 11 & C. $1206 \mathrm{~T}>\mathrm{C}$ & p.P402P & Silent mutation \\
\hline & & 15 & c.1596-8_-6TCT> CCG & & Common allele \\
\hline & & 15 & C. $1692 \mathrm{~T}>\mathrm{C}$ & p.Y564Y & Silent mutation \\
\hline & & 19 & c.2369+5_+8CCCT> GCTG & & Common allele \\
\hline & & 24 & c.3012>TC & p.L1004L & Silent mutation \\
\hline & & 25 & c.3120C>T & p.F1040F & Silent mutation \\
\hline & & 25 & C.3156A>G & p.A1052A & Silent mutation \\
\hline & & 28 & $c .3763 A>G$ & p.M255V & Common allele \\
\hline CTSF & $2-13$ & 1 & C. $169 A>C$ & p.R57R & Silent mutation \\
\hline KCTD7 & $1-4$ & & & & \\
\hline
\end{tabular}


among the control WGSs from healthy dogs or dogs with unrelated diseases and thus are unlikely to cause the Chinese Crested's rare NCL. In contrast MFSD8:c.843delT, the single-base deletion and frame shift, occurred as a homozygous sequence variant in the affected Chinese, but was absent from the 101 control WGSs in our data set.

Figure 6A shows the affected Chinese Crested alignment around MFSD8:c.843delT. This sequence variant was filtered from our earlier search for unique, homozygous, coding variants because it was classified as a heterozygous variant. Visual inspection of the alignment indicated that one of three consecutive deoxythymidines (or $T_{\mathrm{s}}$ ) was deleted. For all reads that spanned this $\boldsymbol{T} T \boldsymbol{T}$ segment the alignment algorithm positioned the deletion at the third (or 3' most) $\boldsymbol{T}$. However, 1 read was initiated within the $\boldsymbol{T} \boldsymbol{T} \boldsymbol{T}$ region and extended in the 3' direction and another read was initiated from the 3' direction and ended within the $\boldsymbol{T T T}$ region. Both of these reads could be perfectly aligned to the reference sequence with a $\boldsymbol{T}$ at position MFSD8:c.843, so the NextGENe software classified the variant at this position as a heterozygous $\boldsymbol{T}$ deletion. In our experience, homozygous partial deletions of tandem repeats have often been misclassified as heterozygous. We now recognize these errors because the reads supporting the deletion alleles are much more numerous than the reads supporting the reference sequence alleles.

MFSD8:c.843delT was predicted to encode MFSD8:p. $F 282 L f S 13 \%$, a truncated variant of the gene product,
MSFD8. MFSD8 is member 8 in the family of mammalian major facilitator superfamily (MFS) domain-containing proteins. The MFS domain consists of 12 transmembrane helices. Although the function of MFSD8 has not been established, other MFS domain-containing proteins transport a diverse variety of substances across biomembranes [37]. MFSD8 is expressed throughout the body [9]. An $\mathrm{N}$-terminal dileucine motif targets the MFSD8 protein to lysosomal membranes [38,39] where it may control the passage of unknown substrates into or out of the lysosomes. The MFSD8:p.F282Lfs 13 * frame shift was predicted to occur within the $7^{\text {th }}$ transmembrane helix and would delete $239 \mathrm{C}$-terminal codons. The resulting truncated protein would lack the $5 \mathrm{C}$-terminal transmembrane helices of the MFS domain and thus be very unlikely to retain function.

In 2007, MFSD mutations were first reported to cause a subtype of human NCL [9], now referred to as CLN7. Since then, a total of at least 22 MFSD mutations have been identified in CLN7 patients [40-43]. In most CLN7 patients, the initial signs occurred between 2 and 5 years of age. Typically, the initial signs were one or more of the following: developmental delay or regression, stereotyped hand movements, seizures, ataxia, and loss of vision. The disease progressed rapidly and most CLN7 patients exhibited myoclonus and mental regression and became wheelchair bound before their $7^{\text {th }}$ birthday. Serial magnetic resonance images from one CLN7 patient 
showed progressive cortical and cerebellar atrophy [39]. Most CLN7 patients have died before their $13^{\text {th }}$ birthday [9,40-43]. The vision loss, ataxia, brain atrophy, and cognitive decline in the Chinese Crested were comparable to the signs reported in children. These signs, however, were not apparent until the dog reached young adulthood. Nonetheless, the earlier onset of excessive licking may have been comparable to the stereotyped hand movements reported in children. No seizures or myoclonus were reported in the dog. Seizures and myoclonus occur late in the course of disease in other canine NCLs $[17,23,44]$, and the Chinese Crested may have been euthanized before those signs would have developed.

A recent report described the creation and characterization of an $M f_{s} d 8$ knockout mouse model [45]. The $M f s d 8$ nullizygous mice had a depletion of retinal photoreceptors and an accumulation of neuronal autofluorescent storage bodies. The ultrastructural appearance of the storage material in these mice was similar to that observed in the affected Chinese Crested dog. However, unlike the human CLN7 patients and our dog, the $M f s d 8$ nullizygous mice did not exhibit any neurologic signs, behavior changes, brain atrophy or premature death [45].

We were eager to confirm our findings in other dogs and, if possible, to establish an MFSD8-deficient animal model that, like the human CLN7 patients, develops neurodegeneration and progressive neurological impairment. We, therefore, devised a TaqMan allelic discrimination assay to genotype archived DNA samples at MFSD8:C.843. The PCR primers for this assay were 5'-CTGTTG TGGCCACTAATATTGTGTT-3' and 5'-TGAAGACAGAA TAAAACTTACGTTTCAAAAAGG-3' and the competing probes were 5'-VIC-CGTGATTCTATTATCTTTG-MBG3' (variant allele) and 5'-FAM-CGTGATTCTATTTATCT TTG-MBG-3' (reference allele). With this assay we genotyped archived DNA samples from 1,478 Chinese Cresteds. All but one of these samples were homozygous for the reference MFSD8:c.843T allele. A single sample was heterozygous for $c .843 \mathrm{delT}$. That sample was obtained for an unrelated analysis in 2010 from a 10-year-old Chinese Crested that lived in Sweden. This indicates that although the mutant allele is rare, it has a widespread geographic distribution.

\section{Conclusions}

Based on the clinical neurological signs, the brain atrophy, the massive accumulation of autofluorescent storage bodies in the brain, and the lamellar ultrastructure of the material within the storage bodies, we conclude that the Chinese Crested's disease should be classified as an NCL. Also, we conclude that the homozygous MFSD8:c.843delT deletion is very likely to be the molecular genetic cause of this NCL. The second conclusion was reached because a variety of mutations in the human ortholog have caused a clinically similar disease in CLN7 patients and because the deletion of $c .843 T$ creates a frame shift predicted to cause the mutant gene to encode a severely truncated protein without function.

Because the MFSD8:c.843delT allele appears to be quite rare even among Chinese Cresteds, we do not believe that commercial DNA testing for the deletion is warranted. Nonetheless, the identification of additional MFSD8: c.843delT homozygous dogs with NCL would be strong added support that this deletion can cause recessive canine NCL. Furthermore, if reproductively intact dogs with this deletion could be identified, they could be the foundation for a research colony to provide an animal model with a disease phenotype that mirrors CLN7 more closely than the current homozygous $M f s d 8$ knockout mouse. The potential value of canine NCL models is illustrated by the canine model for human CLN2 $[17,27,46]$. Preclinical studies using this model served as the basis for an ongoing human clinical trial of enzyme replacement therapy [47]. We have described a distinct young-adultonset neurodegenerative disease of Chinese Cresteds [48] and have used whole-genome sequencing to identify its molecular genetic cause (manuscript in preparation). If veterinarians or researchers have access to unexplained cases of neurodegenerative diseases of Chinese Cresteds (or dogs of other breeds), we would like to help establish molecular genetic diagnoses.

\section{Additional file}

Additional file 1: Table S1. Homozygous, unique coding variants in whole genome sequence of Chinese Crested with NCL.

\section{Abbreviations}

NCL: Neuronal ceroid lipofuscinosis; WGS: Whole genome sequence; MFS: Major facilitator superfamily; GFAP: Glial fibrillary acidic protein.

\section{Competing interests}

The authors declare that they have no competing interests.

\section{Authors' contributions}

$J G$ identified the causal allele in the sequence alignment, genotyped and sequenced samples from individual dogs, and helped to draft the manuscript. DPO analysed the clinical record and helped to draft the manuscript. TM prepared the samples for whole genome sequencing. NJO recognized that the clinical history of the Chinese Crested was consistent with NCL. JFT conceived of our overall strategy for WGS analysis and guided the development of the data analysis pipeline. RDS developed the data analysis pipeline, used the pipeline for pre-alignment sequence manipulation, alignment, and post-alignment variant prioritization, and deposited the sequence data in the Sequence Read Archive. MLK conducted the fluorescence microscopy and the electron microscopy studies and helped to draft the manuscript. GSJ supervised the preparation of the samples for whole genome sequencing and the genotyping and Sanger sequencing of samples from individual dogs and drafted the manuscript with input as previously indicated. All authors read and approved the final manuscript.

\section{Acknowledgements}

This work was supported in part by Mizzou Advantage, the University of Missouri Research Board, and the Batten Disease Support and Research Association. We thank Stacey Sullivan of the Animal Specialty Group, Los Angeles, CA for bringing the case to our attention and Dr. Joan Coates, 
University of Missouri, for supplying us with tissue from a normal healthy dog. We also thank Robert Wayne of the University of California Los Angeles, Matt Huntelman of the Translational Genomics Research Institute, Kate Meurs and Josh Stern of North Carolina State University and Paula Henthorn of the University of Pennsylvania for providing genome sequence data for use as controls.

\section{Author details}

'Department of Veterinary Pathobiology, College of Veterinary Medicine, University of Missouri, Columbia, MO, USA. ${ }^{2}$ Department of Veterinary Medicine and Surgery, College of Veterinary Medicine, University of Missouri, Columbia, MO, USA. ${ }^{3}$ Department of Clinical Sciences, College of Veterinary Medicine, North Carolina State University, Raleigh, NC, USA. ${ }^{4}$ Division of Animal Science, College of Agriculture, Food and Natural Resources, University of Missouri, Columbia, MO, USA. ${ }^{5}$ Mason Eye Institute, School of Medicine, University of Missouri, Columbia, MO, USA.

Received: 26 May 2014 Accepted: 6 August 2014

Published online: 03 January 2015

\section{References}

1. Cooper JD: The neuronal ceroid lipofuscinoses: the same, but different? Biochem Soc Trans 2010, 38:1448-1552.

2. Vesa J, Hellsten E, Verkruyse LA, Camp LA, Rapola J, Santavuori P, Hofmann SL, Peltonen L: Mutations in the palmitoyl protein thioesterase gene causing infantile neuronal ceroid lipofuscinosis. Nature 1995, 376:584-587.

3. Sleat DE, Donnelly RJ, Lackland H, Liu CG, Sohar I, Pullarkat RK, Lobel P. Association of mutations in a lysosomal protein with classical lateinfantile neuronal ceroid lipofuscinosis. Science 1997, 277:1802-1805.

4. The International Batten Disease Consortium: Isolation of a novel gene underlying Batten disease, CLN3. Cell 1995, 82:949-957.

5. Nosková L, Stránecký V, Hartmannová H, Pristoupilová A, Barešová V, Ivánek R, Hulková H, Jahnová H, van der Zee J, Staropoli JF, Sims KB, Tyynelä J, Van Broeckhoven C, Nijssen PC, Mole SE, Elleder M, Kmoch S: Mutations in DNAJC5, encoding cysteine-string protein alpha, cause autosomal-dominant adultonset neuronal ceroid lipofuscinosis. Am J Hum Genet 2011, 89:241-252.

6. Savukoski M, Klockars T, Holmberg V, Santavuori P, Lander ES, Peltonen L: CLN5, a novel gene encoding a putative transmembrane protein mutated in Finnish variant late infantile neuronal ceroid lipofuscinosis. Nat Genet 1998, 19:286-288.

7. Gao H, Boustany RM, Espinola JA, Cotman SL, Srinidhi L, Antonellis KA, Gillis T, Qin X, Liu S, Donahue LR, Bronson RT, Faust JR, Stout D, Haines JL, Lerner TJ, MacDonald ME: Mutations in a novel CLN6-encoded transmembrane protein cause variant neuronal ceroid lipofuscinosis in man and mouse. Am J Hum Genet 2002, 70:324-335.

8. Wheeler RB, Sharp JD, Schultz RA, Joslin JM, Williams RE, Mole SE: The gene mutated in variant late-infantile neuronal ceroid lipofuscinosis (CLN6) and in nclf mutant mice encodes a novel predicted transmembrane protein. Am J Hum Genet 2002, 70:537-542.

9. Siintola E, Topcu M, Aula N, Lohi H, Minassian BA, Paterson AD, Liu XQ, Wilson C, Lahtinen $U$, Anttonen AK, Lehesjoki AE: The novel neuronal ceroid lipofuscinosis gene MFSD8 encodes a putative lysosomal transporter. Am J Hum Genet 2007, 81:136-146.

10. Ranta S, Zhang Y, Ross B, Lonka L, Takkunen E, Messer A, Sharp J, Wheeler R, Kusumi K, Mole S, Liu W, Soares MB, Bonaldo MF, Hirvasniemi A, de la Chapelle A, Gilliam TC, Lehesjoki AE: The neuronal ceroid lipofuscinoses in human EPMR and mnd mutant mice are associated with mutations in CLN8. Nat Genet 1999, 23:233-236.

11. Siintola E, Partanen S, Strömme P, Haapanen A, Haltia M, Maehlen J, Lehesjoki AE, Tyynelä J: Cathepsin D deficiency underlies congenital human neuronal ceroid-lipofuscinosis. Brain 2006, 129:1438-1445.

12. Smith KR, Damiano J, Franceschetti S, Carpenter S, Canafoglia L, Morbin M, Rossi G, Pareyson D, Mole SE, Staropoli JF, Sims KB, Lewis J, Lin WL, Dickson DW, Dahl HH, Bahlo M, Berkovic SF: Strikingly different clinicopathological phenotypes determined by progranulin-mutation dosage. Am J Hum Genet 2012, 90:1102-1107.

13. Bras J, Verloes A, Schneider SA, Mole SE, Guerreiro RJ: Mutation of the parkinsonism gene ATP13A2 causes neuronal ceroid-lipofuscinosis. Hum Mol Genet 2012, 21:2646-2650.

14. Smith KR, Dahl HH, Canafoglia L, Andermann E, Damiano J, Morbin M, Bruni AC, Giaccone G, Cossette P, Saftig P, Grötzinger J, Schwake M, Andermann F, Staropoli JF, Sims KB, Mole SE, Franceschetti S, Alexander NA, Cooper JD,
Chapman HA, Carpenter S, Berkovic SF, Bahlo M: Cathepsin F mutations cause Type B Kufs disease, an adult-onset neuronal ceroid lipofuscinosis. Hum Mol Genet 2013, 22:1417-1423.

15. Staropoli JF, Karaa A, Lim ET, Kirby A, Elbalalesy N, Romansky SG, Leydiker KB, Coppel SH, Barone R, Xin W, MacDonald ME, Abdenur JE, Daly MJ, Sims KB, Cotman SL: A homozygous mutation in KCTD7 links neuronal ceroid lipofuscinosis to the ubiquitin-proteasome system. Am J Hum Genet 2012, 91:202-208.

16. Sanders DN, Farias FH, Johnson GS, Chiang V, Cook JR, O'Brien DP, Hofmann SL, Lu JY, Katz ML: A mutation in canine PPT1 causes early onset neuronal ceroid lipofuscinosis in a Dachshund. Mol Genet Metab 2010, 100:349-356.

17. Awano T, Katz ML, O'Brien DP, Sohar I, Lobel P, Coates JR, Khan S, Johnson GC, Giger U, Johnson GS: A frame shift mutation in canine TPP1 (the ortholog of human CLN2) in a juvenile Dachshund with neuronal ceroid lipofuscinosis. Mol Genet Metab 2006, 89:254-260.

18. Melville SA, Wilson CL, Chiang CS, Studdert VP, Lingaas F, Wilton AN: A mutation in canine CLN5 causes neuronal ceroid lipofuscinosis in Border collie dogs. Genomics 2005, 86:287-294

19. Katz ML, Farias FH, Sanders DN, Zeng R, Khan S, Johnson GS, O'Brien DP: A missense mutation in canine CLN6 in an Australian shepherd with neuronal ceroid lipofuscinosis. J Biomed Biotechnol 2011, 2011:198042.

20. Katz ML, Khan S, Awano T, Shahid SA, Siakotos AN, Johnson GS: A mutation in the CLN8 gene in English setter dogs with neuronal ceroidlipofuscinosis. Biochem Biophys Res Commun 2005, 327:541-547.

21. Guo J, Johnson GS, Brown HA, Provencher ML, Da Costa RC, Mhlanga-Mutangadura T, Taylor JF, Schnabel RD, O'Brien DP, Katz ML: A CLN8 nonsense mutation in the whole genome sequence of a mixed breed dog with neuronal ceroid lipofuscinosis and Australian Shepherd ancestry. Mol Genet Metab 2014, 112:302-309.

22. Awano T, Katz ML, O'Brien DP, Taylor JF, Evans J, Khan S, Sohar I, Lobel P, Johnson GS: A mutation in the cathepsin D gene (CTSD) in American Bulldogs with neuronal ceroid lipofuscinosis. Mol Genet Metab 2006, 87:341-348

23. Farias FH, Zeng $R$, Johnson GS, Wininger FA, Taylor JF, Schnabel RD, McKay SD, Sanders DN, Lohi H, Seppälä EH, Wade CM, Lindblad-Toh K, O'Brien DP, Katz ML: A truncating mutation in ATP13A2 is responsible for adult-onset neuronal ceroid lipofuscinosis in Tibetan terriers. Neurobiol Dis 2011, 42:468-474.

24. Wöhlke A, Philipp U, Bock P, Beineke A, Lichtner P, Meitinger T, Distl O: A one base pair deletion in the canine ATP13A2 gene causes exon skipping and late-onset neuronal ceroid lipofuscinosis in the Tibetan terrier. PLoS Genet 2011, 7:e1002304.

25. Abitbol M, Thibaud JL, Olby NJ, Hitte C, Puech JP, Maurer M, Pilot-Storck F, Hédan B, Dréano S, Brahimi S, Delattre D, André C, Gray F, Delisle F, Caillaud C, Bernex F, Panthier JJ, Aubin-Houzelstein G, Blot S, Tiret L: A canine Arylsulfatase $\mathrm{G}$ (ARSG) mutation leading to a sulfatase deficiency is associated with neuronal ceroid lipofuscinosis. Proc Natl Acad Sci U S A 2010, 107:14775-14780.

26. Kowalewski B, Lamanna WC, Lawrence R, Damme M, Stroobants S, Padva M, Kalus I, Frese MA, Lübke T, Lüllmann-Rauch R, D'Hooge R, Esko JD, Dierks T: Arylsulfatase $\mathrm{G}$ inactivation causes loss of heparan sulfate 3-O-sulfatase activity and mucopolysaccharidosis in mice. Proc Natl Acad Sci U S A 2012, 109:10310-10315.

27. Vuillemenot B, Katz ML, Coates JR, Lobel P, Tiger P, Bunting S, Kanazono S, Kennedy D, Tsuruda L, O'Neill C: Intrathecal tripeptidyl peptidase-1 reduces Lysosomal Storage in a Canine Model of LINCL. Mol Genet Metabol 2011, 104:325-337.

28. Wininger FA, Zeng R, Johnson GS, Katz ML, Johnson GC, Bush WW, Jarboe JM, Coates JR: Degenerative myelopathy in a Bernese mountain dog with a novel SOD1 missense mutation. J Vet Intern Med 2011, 25:1166-1170.

29. Eng LF, Ghirnikar RS, Lee YL: Glial fibrillary acidic protein: GFAP-thirty-one years (1969-2000). Neurochem Res 2000, 25:1439-1451.

30. Sofroniew MV, Vinters HV: Astrocytes: biology and pathology. Acta Neuropathol 2010, 119:7-35.

31. O'Brien DP, Katz ML: Neuronal ceroid lipofuscinosis in 3 Australian shepherd littermates. J Vet Intern Med 2008, 22:472-475.

32. Katz ML, Johnson GS, Tullis GE, Lei B: Phenotypic characterization of a mouse model of juvenile neuronal ceroid lipofuscinosis. Neurobiol Dis 2008, 29:242-253.

33. Zimin AV, Marcais G, Puiu D, Roberts M, Salzberg SL, Yorke JA: The MaSuRCA genome assembler. Bioinformatics 2013, 29:2669-2677. 
34. Lu JY, Hofmann SL: Thematic review series: lipid posttranslational modifications. lysosomal metabolism of lipid-modified proteins. J Lipid Res 2006, 47:1352-1357.

35. Livak KJ: Allelic discrimination using fluorogenic probes and the 5 nuclease assay. Genet Anal 1999, 14:143-149.

36. Beigneux A, Withycombe SK, Digits JA, Tschantz WR, Weinbaum CA, Griffey SM, Bergo M, Casey PJ, Young SG: Prenylcysteine lyase deficiency in mice results in the accumulation of farnesylcysteine and geranylgeranylcysteine in brain and liver. J Biol Chem 2002, 277:38358-38363.

37. Yan N: Structural advances for the major facilitator superfamily (MFS) transporters. Trends Biochem Sci 2013, 38:151-159.

38. Steenhuis P, Herder S, Gelis S, Braulke T, Storch S: Lysosomal targeting of the CLN7 membrane glycoprotein and transport via the plasma membrane require a dileucine motif. Traffic 2010, 11:987-1000

39. Sharifi A, Kousi M, Sagné C, Bellenchi GC, Morel L, Darmon M, Hulková H, Ruivo R, Debacker C, El Mestikawy S, Elleder M, Lehesjoki AE, Jalanko A, Gasnier B, Kyttälä A: Expression and lysosomal targeting of CLN7, a major facilitator superfamily transporter associated with variant late-infantile neuronal ceroid lipofuscinosis. Hum Mol Genet 2010, 19:4497-4514.

40. Aiello C, Terracciano A, Simonati A, Discepoli G, Cannelli N, Claps D, Crow YJ, Bianchi M, Kitzmuller C, Longo D, Tavoni A, Franzoni E, Tessa A, Veneselli E, Boldrini R, Filocamo M, Williams RE, Bertini ES, Biancheri R, Carrozzo R, Mole SE, Santorelli FM: Mutations in MFSD8/CLN7 are a frequent cause of variant-late infantile neuronal ceroid lipofuscinosis. Hum Mutat 2009, 30:E530-E540

41. Stogmann E, El Tawil S, Wagenstaller J, Gaber A, Edris S, Abdelhady A, Assem-Hilger E, Leutmezer F, Bonelli S, Baumgartner C, Zimprich F, Strom TM, Zimprich A: A novel mutation in the MFSD8 gene in late infantile neuronal ceroid lipofuscinosis. Neurogenetics 2009, 10:73-77.

42. Aldahmesh MA, Al-Hassnan ZN, Aldosari M, Alkuraya FS: Neuronal ceroid lipofuscinosis caused by MFSD8 mutations: a common theme emerging Neurogenetics 2009, 10:307-311.

43. Kousi M, Siintola E, Dvorakova L, Vlaskova H, Turnbull J, Topcu M, Yuksel D, Gokben S, Minassian BA, Elleder M, Mole SE, Lehesjoki AE: Mutations in CLN7/MFSD8 are a common cause of variant late-infantile neuronal ceroid lipofuscinosis. Brain 2009, 132:810-819.

44. Koppang N: English setter model and juvenile ceroid-lipofuscinosis in man. Am J Med Genet 1992, 42:599-604.

45. Damme M, Brandenstein L, Fehr S, Jankowiak W, Bartsch U, Schweizer M Hermans-Borgmeyer I, Storch S: Gene disruption of Mfsd8 in mice provides the first animal model for CLN7 disease. Neurobiol Dis 2014, 65:12-24.

46. Katz ML, Coates JR, Cooper JJ, O'Brien DP, Jeong M, Narfström K: Retinal pathology in a Canine Model of Late Infantile Neuronal Ceroid Lipofuscinosis. Invest Ophthalmol Vis Sci 2008, 49:2686-2695.

47. Katz ML, Coates JR, Sibigtroth CM, Taylor JD, Carpentier M, Young WM Wininger FA, Kennedy D, Vuillemenot BR, O'Neill CA: Enzyme replacement therapy attenuates disease progression in a Canine Model of Late Infantile Neuronal Ceroid Lipofuscinosis (CLN2 Disease). J Neurosci Res 2014, 92:1591-1598.

48. O'Brien DP, Johnson GS, Schnabel RD, Khan S, Coates JR, Johnson GC, Taylor JF: Genetic mapping of canine multiple system degeneration and ectodermal dysplasia loci. J Hered 2005, 96:727-734.

\section{Submit your next manuscript to BioMed Central and take full advantage of:}

- Convenient online submission

- Thorough peer review

- No space constraints or color figure charges

- Immediate publication on acceptance

- Inclusion in PubMed, CAS, Scopus and Google Scholar

- Research which is freely available for redistribution 